\title{
The Impact of Childhood Malnutrition on Schooling:
}

\section{Evidence from Bangladesh}

\author{
Rasheda Khanam ${ }^{\mathrm{a}}$, Hong Son Nghiem ${ }^{\mathrm{b}}$ and Mohammad Mafizur Rahman ${ }^{\mathrm{c}}$
}

\begin{abstract}
This paper examines the impact of childhood malnutrition on schooling performance in rural Bangladesh. The results reveal that malnourished children are less likely to enrol in school on time and achieve an age appropiate grade by 26 percentage points and 31 percentage points, respectively. Other important determinants of schooling outcomes include infrastructure and education level of parents. One major contribution of this paper is the control for the endogeneity of malnutrition status, which otherwise may lead to bias estimates.
\end{abstract}

Keywords: Malnutrition, Schooling, South Asia, Bangladesh

JEL Classification: I12, I21,O12.

${ }^{a}$ Corresponding author, rasheda.khanam@usq.edu.au; Phone: 6174631 1256; Fax: + 6174631 5594; School of Accounting, Economics and Finance, University of Southern Queensland.

${ }^{\mathrm{b}}$ Centre of National Research on Disability and Rehabilitation Medicine (CONROD), University of Queensland.

${ }^{\mathrm{c}}$ School of Accounting, Economics and Finance, University of Southern Queensland 


\section{Introduction}

Health in childhood has a long lasting effect on schooling (Lawlor et al., 2006; Black et al., 2007; Gregg et al., 2005; Oreopoulos et al., 2008; Currie and Moretti, 2007), future health and earning (Case et al., 2005; Johnson and Schoeni, 2007; Smith, 2007). Poor health in childhood can affect schooling directly by missing school days and indirectly by affecting cognition. Thus children with poor health are likely to have lower human capital (both in terms of schooling and health), which negatively affects their productivity and income in the future. In fact, health status and school attainment are complementary. Good health and education can lead to a higher future standard of living (Schultz, 1999). Therefore, investment in human capital is crucial for increasing productivity, which in turn enhances economic development.

Bangladesh is a poor country of South Asia, with 41.3 per cent of its 138 million population live on less than US\$1 per day during the 1990-2005 period. The country's infant mortality rate (per 1000 live births) and under-5 mortality rate (per 1000 children) are, 46 and 69 respectively (United Nations Development Program, 2005). The Bangladesh Demographic Health Survey (BDHS)-2004 notes that 43 per cent of Bangladeshi children under 5 years of age are short for their age or stunted, and 17 per cent are severely stunted. Additionally, 13 per cent of the Bangladeshi children are seriously underweight for their height, or wasted, and one per cent is severely wasted. Forty eight per cent of children are considered underweight (low weight for age), and 13 per cent are classified as severely underweight (ESCAP, 2005). 
Early childhood malnutrition is widely perceived to affect various areas of child development, including cognitive achievement. In this study we look at the impact of child nutrition on educational achievements of Bangladeshi children using a regional data set from Bangladesh. A better understanding of the association between child health and schooling is essential for a rapid expansion of education and economic development in developing countries through increased human capital investment.

An extensive literature reviewed by Pollitt (1990) and Behrman (1996) reported a significant positive association between child nutritional status and school performance. For example, studies of Chutikul (1986) in Thailand, Moock and Leslie (1986) in Nepal, Jamison (1986) in China, and Harbison and Hanushek (1992) in Brazil found a positive association between grade attainment and child nutrition. However, most of the previous studies did not consider the fact that child nutrition status is endogenous. One source of the endogeneity is due to unobserved individual effects that create a correlation between child nutrition and the error term in regression analyses. Also, child health and schooling performance both reflect household decisions regarding investments into children's human capital, which is determined simultaneously in the household. Some studies that take into account the endogeneity of child health such as Glewwe and Jacoby (1995), Behrman and Lavy (1997), Glewwe et al. (2001), Alderman et al. (2001), Grira (2004), and Handa and Peterman (2007) found the effects of child health on schooling were considerably lower. Previous studies that control for the endogeneity of child health used primarily instrumental variable (IV) approach with lags of exogenous variables such as prices were used as IV. This approach is practically difficult to apply in a cross-sectional data like the current study. We overcome this difficulty by exploiting the unique characteristics of a simultaneous bivariate probit model in which the likelihood 
function remains the same whether or not the endogeneity issue is taken into account (Greene, 1998). This option is possible because both dependent variable (school performance) and endogenous variable (malnutrition) are dichotomous in this study. Our selected estimator is essentially a full information maximum likelihood (FIML) that is consistent with the economic theory of household and able to control the endogeneity of child nutritional status.

\section{Methodology}

\subsection{Economic Model}

The relationship between child health and schooling performance can be explained using the household production model by Becker (1965), Becker and Lewis (1973), Singh et al. (1986), and Taylor and Adelman (2003). Essentially, in these models households are assumed to maximise their expected life time utility given the time and budget constraint. Households get utility from the consumption of goods and services (self-produced and purchased) and the enjoyment of leisure activities. The households generate income from production activities such as work in the family farm or in waged employment. Therefore, the households face an optimisation task that aim to achieve the highest level of utility by allocating the fixed time constraint (e.g., 24 hours a day) between production, consumption and leisure.

Education and health care are examples of services that households consume. The households get higher utility from good schooling performance and good health of their children. In order to achieve this outcome, they have to allocate some household resources

towards education and health care for their children (e.g., food, clothing, and school fee). Apart from common determinants such as budget constraint and other exogenous 
characteristics, the amount of resources that households allocate to education and health of their children are decided by unobservable characteristics such as taste and preferences. These unobserved characteristics are the main factor causing the endogeneity of child health in schooling performance analaysis.

\subsection{Econometric Specification}

Based on the reasoning from the household economic model, basic econometric specification to estimate the impact of childhood malnutrition on schooling is:

$$
\begin{gathered}
S_{i}=\alpha_{0}+\alpha_{1} H_{i}+\alpha_{2} X_{i}+\varepsilon_{i} \\
H_{i}=\beta_{0}+\beta_{1} Z_{i}+\eta_{i}
\end{gathered}
$$

where $S_{i}$ is an indicator for child schooling; $H_{i}$ is the health status of a child which is measured by a dummy variable that equals to one if the height-for-age of the child is less than 2 standard deviations compared to the reference population of the same age and sex (hereinafter we refer to this dummy variable as stunting); $X_{i}$ and $Z_{\mathrm{i}}$ are sets of exogenous variables that includes child characteristics (age and gender), household characteristics (parental education, wealth and sanitation practice), and community characteristics (e.g., availability of schools, distance to doctors and availability of grid electricity); and $\varepsilon_{\mathrm{i}}$ and $\eta_{\mathrm{i}}$ are random errors.

A household is likely to take decisions regarding investment into child schooling and health simultaneously. Therefore, the child health variable in equation (1) might be endogenous. One factor causing this endogeneity is unobserved individual effects that affecting both child health and schooling, captured in the error term $\varepsilon_{i}$ (i.e., $\varepsilon_{i}$ and $H_{i}$ are 
correlated). Therefore, the estimation of equation (1) considering child health as an exogenous variable might provide inconsistent estimates and hence the results might be biased. One way to address this issue is the use of instrumental variables, where one needs to find a set of covariates that affect child health without affecting child schooling as instrumental variables. However, finding a good instrument is often practically difficult. In the data set of this study, we could not find any variable with that quality.

Greene (1998) shows that in the case of a probit model with a binary endogenous variable, one can obtain a consistent estimate using maximum likelihood approach without the need of an instrumental variable. This action is feasible because the maximum likelihood function of a bivariate probit model remains the same when the endogeneity issue is taken into account (Greene 1998, p.295). Therefore, in this study we estimate equation (1) and (2) jointly using a bivariate probit model. This approach estimates the correlation between $H_{i}$ and $\mathcal{E}_{i}$ in equation (1) simultanously with parameters of both equations. The significance of this correlation coefficient can be interpreted as a test for the null hypothesis that child health is exogenous.

\section{Data and Variable Selection}

\subsection{Data Source}

The data set used in this study comes from a survey titled "Micronutrient and Gender Study (MNGS) in Bangladesh", administered by the International Food Policy Research Institute (IFPRI). The MNGS was conducted using a multi-stage clustered sampling process where the first stage involved the selection of three survey sites: Saturia, Mymensingh and Jessore 
(IFPRI, 2001). The next step involved the random selection of representive villages within sites. Finally, households were sampled randomly from each selected village. Overall, the survey sample includes 5,541 individuals from 957 households in 47 villages of the three selected sites. The survey data were collected in four rounds from June 1996 to September 1997, covering demographic chracteristics, education, health and socio-economic activities. This coverage was designd to examine the extent to which intrahousehold resources allocation processes affect development outcomes. In addition, IFPRI aimed to make the data of this survey comparable with similar surveys they conducted in other countries.

This study restricts the sample only to the children of the first round of the survey, because other rounds included only those adult household members who were away from home at the time of the first round of the survey. These household members only account for a very small proportion of the total sample, hence it is expected that they do not affect the analysis. Also, we select children aged 5-17 years living in rural households in which the mother and father are both present, thus, the final sample include 1441 observations.

\subsection{Descriptive Statistics}

The descriptive statistics of the variables used in this study, reported in Table 1, show that children in our sample have a mean height-for-age that is slightly less than two standard deviations below than that of the reference population. Table 1 also shows that 79 per cent of the children in the sample are currently attending school but only 44 per cent are enrolled by the due age. This is probably the main factor leading to 53 per cent of the children in the sample not achieving the right grade for their age (after adjusted for the actual age of enrollment the poor performance rate is only 19 per cent). The sample also shows that only 39 
per cent of the children surveyed are girls. A low proportion of girls sampled in this study may be due to the fact that some girls, especially those round the upper bound of the age range (17 years old) could be married, and hence they are not included in the sample as household members. Also we only consider the son/daughter of the household head, so daughter-in-laws are also excluded from the sample. The household characteristics show that the proportion of fathers who can read and write is double than that of mothers although it is relatively low for both groups (44 vs 23 per cent). The sanitary condition, which is an important factor that determines child health, is rather modest. Only 24 per cent of the households have a sanitary latrine; 65 per cent have a clean housing condition; and 59 per cent of the households practice washing hands before meals. The basic infrastructure of the communities surveyed is rather poor. Only 65 per cent of the communities has a primary school, whilst the availability of secondary schools for girls and both sexes are only 5 and 12 per cent, respectively. On average, only 24 per cent of the communities are connected to electricity. The distance to a nearest MBBS doctor is $21 \mathrm{~km}$, which seems to be distorted by some remote communities as the median distance is only $10 \mathrm{~km}$.

\section{- TABLE 1 IS ABOUT HERE -}

The data also show that in most measures of schooling of this study, stunted children seem to perform worse than others (see Table 2). For example, the attendance rate of children with normal height-for-age is 82 per cent whilst that of stunted children is only 80 per cent. Children with normal height-for-age are about twice likely (57 vs 29 per cent) to enrol at the appropriate age (six years old in Bangladesh) compared to stunted children. Finally, the rate of 
children who are falling behind in school progress (i.e., have lower grade than their age) is 38 per cent for normal children, which is much lower than 68 per cent of stunted children. However, after adjusting for the actual age of enrollment, the proportion of poorly performed children about stunted and normal children are almost identical at 18.7 and 19 per cent,

respectively. A basic $\chi^{2}$ test revealed that only the incidence of late enrollment and unadjusted grade attainment of children in the two group differ significantly at one per cent. Note that the comparison in Table 2 did not control for characteristics of the child, household and the community, which may affect the relationship between child health and schooling. This will be investigated further in regression analyses.

\section{— TABLE 2 IS ABOUT HERE -}

\subsection{Choice of Variables}

Child health in this study is measured by height-for-age, which is an important indicator of malnutrition (Waterlow, 1972) and widely used in the literature as a measure of childhood malnutrition. The z-score method, recommended by the World Health Organisation (WHO), is used to measure a child's height-for-age. The z-score measures the degree to which a child's measurements deviate from what is expected for that child, based on a WHO/NCHS international reference population. In other words, the height-for-age is expressed as a number of standard deviations above or below the corresponding reference mean for a child of the same age and sex. Based on the guideline of the WHO (de Onis and Blössner, 1997), we construct a dummy variable representing the malnutrition status that equals to one if a child 
has the z-score of height-for-age less than -2 (i.e., has height or weight which fall below two standard deviations from the mean of the reference population of the same age and sex).

We examine three binary measures of child's schooling: attendance (equals to one if the child is attending school), enrolment (equal to one if the child is enrolled at school at six years of age) and grade attainment (equal to one if the child achieves right grade for his/her age). Test score could be an obvious measure of schooling performance but unfortunately this measure is unavailable in our data set.

With the third measure of schooling, we hypothesise that child health not only affects his/her school enrolment or attendance, but also affects his/her grade attainment. Malnourished children might have lower progress in school because of missed school days, and lack of concentration in preparing home work. Therefore, we also measure child's grade attainment at school. A commonly used measure of grade attainment is "schooling-for-age" (SAGE), which measures schooling attainment relative to age (i.e. whether a child is in the right grade for his/her age). This measure also considers late enrolment. For example, children who are enrolled late will not be in the right grade for their age. This measure of school attainment is widely used in the literature (see, for example, Psacharopoulos and Patrinos, 1997; Ray and Lancaster, 2005; and Khanam and Ross, 2008) as a reliable measure of school outcome in the developing countries. Psacharopoulos and Patrinos (1997), and Ray and Lancaster (2005) defined SAGE as follows:

$$
S A G E=\{\text { Current grade } /(\text { Age }-E)\} \times 100
$$

where $E$ represents the country-specific usual school entry age, which is 6 years in Bangladesh. The SAGE might take values of 100 or higher (i.e., the attainment of the highest 
possible grade attained to date) to 0 (i.e. never attended school). A score of more than 100 indicates that the child has attended more years of school possible for his age (this is possible because although official enrolment age in Bangladesh is 6 years, some parents enrol their children earlier). A score of less than 100 indicates that the child is 'falling behind' in his/her education. Based on Patrinos and Psacharopoulos (1997), and Ray and Lancaster (2005), we converted $S A G E$ to a dichotomous variable, such as $S_{i}$ that takes the value of one if a child has normal progress (i.e., $S A G E<100$ ), and 0 otherwise. The dummy form of $S A G E$ is more useful than the original $S A G E$ score as estimates found from the dummy $S A G E$ can be intuitively interpreted as the probability of attaining the right grade or falling behind in schooling progress. It is surprising that there are only 37 per cent of children in our data set who achieve - right grade for their age (see Table 1). The majority of this group may be due to late enrolment as there was only 35 per cent of children in the sample enrolled school at the appropriate age.

As in equation (3) $E$ captures only the official enrolment age (e.g., 6 years), it is obvious that those enrol later than the official enrolment are certainly belong to the low grade attainment group. Usual measure of $S A G E$ captures both late enrolment and grade repetition. In order to seperate 'grade repetition' from 'late enrolment', we adjust $S A G E$ according to the age at initial enrollment for each child (i.e., in equation 3, E refers to the actual enrolment age). In particular, in second measure of $S A G E$ we define attainable grade as the difference between the child age and the age at initial enrollment. Thus, an age-adjusted performance is defined as those who have actual grade that is lower than this attainable grade. Using this criteria, there are only 19 per cent of children in the sample performed poorly at school. 
As mentioned earlier, we use three groups of exogenous variables to control for the relationship between child nutrition and school performance: child, households and community characteristics. Main variables represent child characteristics include age and gender. At household level, we include information on wealth level (proxied by log of household expenditure), househod size, education level of parents (proxied by their ability to read and write) and hygine practices (proxied by housing condition, hand wash and the availability of latrine). It is expected that children from wealthier households are more likely to have better health status due to the ability of their parents to afford (for example, more nutritious food and/or medicines). Similarly, we expect that children of more hygine households (e.g., clean house, having lactrine and practice wash hand before meals) are more likely to have better health. The effect of household size is expected to be detrimental to both health and education of children because more people are competing for the household resource pool.

At the community level, we select variables that represent basic infrastructure for health and education (for example, avaiability of school, electricity and distance to nearest doctors). We choose availability of schools, which is widely used in the literature as a measure of schooling costs in the absence of real costs of schooling, to proxy cost of schooling. Note that the costs of schooling involve direct costs (e.g., school fees) and indirect costs (e.g., time required to travel to school). The availability of school captures mainly the second component of schooling costs. Likewise, the distant to nearest doctors captures the accessibility of children to health services. The availability of electricity proxies the accessibility to mordern facilities that may lead to higher quality education and health services (e.g., computer, electric lights and fans in class rooms, refrigerators to store vaccine in health clinics). It is expected 
that all these community characteristics have positive effects on both health and education outcomes.

The education and health of children may also be affected by unobserved community characteristics (e.g., customs, attitude toward education, school quality, etc). For example, one community may have richer tradition or higher preferences for child education than others. In order to control for unobservable characteristics of each community that may affect both child health and schooling we employ a dummy variable for each community (choosing arbitrarily one community as a reference).

\section{Results}

This section presents the joint estimates of equation (1) and (2), examining the relationship between child nutrition (proxied by stunting in this study) and the current school attendance, enrolment and grade attainment. As mentioned previously, it is possible that child health is endogenous in the relationship with education, because a household might take the decision to invest in child health and schooling simultaneously. This endogeneity issue can be considered without any exclusion of restriction using a bivariate probit model.

\subsection{School Attendance}

Our results from the school attendance equation show that malnutrition (measured by stunting) does not affect a child's school attendance (see Table 3), which is in line with the basic comparison in Table 2. The correlation coefficient $(\rho)$ is not statistically significant, 
suggesting that there is no endogeneity issue of stunting with regard to school attendance. Therefore, the results would still be consistent if one estimates equation (1) using only probit estimator.

Factors significantly associated with school attendance are parents' education, and school infrastructure, particularly the availability of secondary girls' school in the community. The marginal effects show that children in a community, where a girls' secondary school is available, have the higher probability of attending school than those without by 51.4 percentage points. Meanwhile, the avaialbility of mixed school only increases the probability of enrolling by 26.4 percentage point. One possible reason is that parents may be more encouraged to send their daughters to school in a community where girls' school is available. Also, the availability of secondary school in the community proxies for cheaper schooling cost (indirect costs), and hence parents are more encouraged to send children to school.

\section{- TABLE 3 IS ABOUT HERE -}

The results also suggest that educated parents are more likely to send their children to school. Particularly, children whose mother and father were able to read and write have an increasing probability of attending school by 14 and 10 percentage points, respectively. It is surprising to see that girls have a higher probability of attending school than that of boys, but this result is not significant. In contrast to our expectation, the household expenditure has no significant effect on school attendance although it significantly reduces the probability of child 
stunting as expected. Other household and community chracteristics also have no effect on the probability that a child being able to attend school.

\subsection{School Enrolment}

Our results show that child health has a significant effect on the probability of due enrolment. The insignificance of the correlation coefficient $(\rho)$ suggests that the results may not be biased if the issue of unobserved heterogeneity is ignored. The marginal effects reveal that a stunted child has lower probability of due enrolment by 26.7 percentage points (see Table 4). This result is in line with other cross-sectional studies such as Glewwe and Jacoby (1995), Behrman and Lavy (1998. Parental education is again proved to be a significant determinant of children's schooling outcome. The probability of being able to enrol in school in due age increased by 15 percentage point for those whose mother are able to read write. Similarly, children in communities with the availability of either girls' secondary school or mixed-sex secondary school have higher probability of enrolling in due time. One possible explanation of these results is that communities with a secondary school will also have a primary school as these are often more advanced communities. Also, the availability of secondary school is a proxy for education infrastructure. We expect that in these communities (with better education infrastructure) parents will have a higher incentive to enrol their children on time; because at least the indirect costs of sending children to school are cheaper. However, the magnitude of the girls' school is almost double than that of the mixed school, which is somehow reflecting the effects of the dominant Muslim culture in the study areas (i.e., parents are more willing to send daughters to girls' secondary schools than to mixed-sex schools). Regarding the stunting 
equation, important factors that contribute to the improvement of child nutrition are household wealth (proxied by expenditure) and hygine environment (proxied by clean housing condition). Nevertheless, it seems that the practice of washing hand has counter intuitive (positive) effect on the probability of stunting although it is only significant at 10 per cent.

\section{— TABLE 4 IS ABOUT HERE -}

\subsection{Grade Attainment}

Table 5 shows that health has an expected and significant effect on grade attainment measured by SAGE. The marginal effects show that a stunted child has a lower probability of achieving age appropiate grade by 31.9 percentage points. The negative and significant effect of child age is not surprising in a country like Bangladesh as an older child is more likely to fall behind in grade attainment due to the increased opportunity costs of schooling. One possible reason is: an older child can earn money from outside work or help his/her parents in housework/agricultural activities. Other significant determinants have similar behaviour as in other schooling measures: children from educated parents (i.e., proxied by being able to read and write) have a higher probability of achieving the expected grade. The availability of girls' secondary school has a stronger effect on grade attainment than mixed-sex secondary school, which also has a significantly higher rate of achieving age appropiate grade compared to that of communities without a secondary school.

\section{— TABLE 5 IS ABOUT HERE —}


As discussed earlier, this measure of $S A G E$ considers both late enrolment and grade repetition, therefore, it provides a lower grade attainment for children who enrolled at school late. To seperate late enrolment from grade repetition, we run another regression to consider for grade attainment adjusting actual enrolment age for each child. Our aim is to look at whether malnutrition has any impact on grade repetition. The result shows that stunting condition does not significantly affect school performance if late enrolment is adjusted, despite it still has the expected negative sign. In addition, after adjusted for late enrollment, it is revealed that older children are significantly more likely to perform better at school. There are almost no other significant derminants of the adjusted school attainment. The only exception is parental education: children of literate fathers and mothers have significantly higher probability of achieving the age appropiate grade

\section{Discussion and Policy Implications}

The crucial role of human capital in economic growth and poverty alleviation is widely investigated, but most studies did not take into account the endogeneity of child health. This study improves our understanding on the relationship between child health and schooling in several ways. First, an estimation method is used that is consistent with the economic theory of household and takes into account the unobserved heterogeneity issues without the need of instrumental variables. Second, we are not aware of any study that has examined the impact of child health on schooling outcome in Bangladesh except Grira (2004). However, as mentioned earlier that the use of household and community variables as the instruments of child health in Grira's study may not completely control for the unobserved hetrogeneity issue. This study 
overcomes this issue using a FIML method using a comparatively newer data set. Finally, in this study the effects of child health (proxied by malnutrition status) on a wide range of schooling measures- enrolment, attendance and attainment- are examined. It is hypothesised that child health affects not only enrolment probability but also school outcome. The results reveal that childhood malnutrition has significant and expected effects on school enrolment, and grade attainment, although it does not affect current school attendance. Therefore, this study adds considerably to the understanding of the impact of child malnutrition on schooling.

Our results indicate that malnourished children are significantly more likely to enrol school later than the due age. Particularly, stunting children have lower probability of enrolling by due age by 26.7 percentage points. This study, however, do not show a statistically significant effect of child health on current school attendance (whether a child was attending school during the survey). This finding is not surprising because current school attendance reflects a current activity, which might not be affected by child health measured by stunting (long-term chronic malnutrition). We have also found that, after adjusted for actual enrolled age, the grade attainment of children was not affected by stunting condition. Other important determinants of schooling are parents' wealth, education and the availability of a secondary school, especially a girls' secondary school in the community. These variables affect schooling outcomes positively.

We caution the readers to interpret the results carefully, because child health in this study is measured during the survey, when the average age of the sampled children is 11 years. Without the availability of longitudinal data we can neither measure child health during the time of first enrolment or before the age of 6 years. However, there is a significant body of 
evidence that suggests that past health status is a significant predictor of the current health (e.g., Murasko, 2008; Khanam et al. 2009).

Our findings have important policy implications. Although we find many factors affecting child schooling, our main focus was on child nutrition as per as policy is concerned. Since we find strong evidence that malnourished children are more likely to enrol late, and fall behind in grade attainment, policy makers of the government, non-government organisations and international bodies should take such initiatives that target early nutrition program and increase social awareness about the importance of early child nutrition and educate parents about nutrition. In addition, development programs that improve livelihood of rural households (e.g., increase of income and consumption, and improvement of literacy and numeracy for adults) may create spill-over effects of improving child nutrition and schooling outcomes. 


\section{Tables}

Table 1: Descriptive statistics

\begin{tabular}{lrrr}
\hline Variable Description & Mean & Median & Std. \\
\hline Health and schooling & & & \\
Height-for-age (z-score) & -1.90 & -1.94 & 1.08 \\
Stunting (1=yes) & 0.48 & 0.00 & 0.50 \\
School attendance (1=if the child is currently attending school) & 0.79 & 1.00 & 0.41 \\
Enrolled in due time (1=enrolled school at the appropriate age) & 0.44 & 0.00 & 0.50 \\
Grade attainment (1=if the child is in right grade for his/her age ) & 0.38 & 0.00 & 0.49 \\
Age-adjusted grade attainment (1=achieves normal grade) & 0.81 & 1.00 & 0.39 \\
Child's age (in years) & 11.16 & 11.00 & 3.46 \\
Gender of the child (female=1) & 0.39 & 0.00 & 0.49 \\
Household characteristics & & & \\
Total household member & 6.51 & 6.00 & 2.77 \\
Log of household expenditure & 2.96 & 2.91 & 0.35 \\
Father can read and write (1=yes) & 0.44 & 0.00 & 0.50 \\
Mother can read and write (1=yes) & 0.23 & 0.00 & 0.42 \\
Sanitary latrine (1=has a sanitation latrine) & 0.24 & 0.00 & 0.43 \\
Housing condition (1=clean) & 0.65 & 1.00 & 0.48 \\
Hand wash (1=always wash hand before meals) & 0.59 & 1.00 & 0.49 \\
Community characteristics & & & \\
Primary school (1= if there is a primary school in the community) & 0.65 & 1.00 & 0.48 \\
Secondary girls' school (1= if there is) & 0.05 & 0.00 & 0.21 \\
Secondary boys' and girls' school (1= if there is) & 0.12 & 0.00 & 0.33 \\
Electricity (1=electricity is available) & 0.24 & 0.00 & 0.43 \\
Distance to nearest MBBS doctor (km) & 21.99 & 10.00 & 40.66 \\
\hline
\end{tabular}


Table 2: Percentage of children by schooling and health status

\begin{tabular}{lcc}
\hline Schooling measures & \multicolumn{2}{c}{ Stunting (\%) } \\
& No & Yes \\
\hline $\begin{array}{l}\text { School attendance } \\
\quad \text { Currently attending school }\end{array}$ & 81.78 & 80.03 \\
$\begin{array}{l}\text { School enrolment } \\
\quad \text { Enrolled school at the appropriate age *** }\end{array}$ & 56.68 & 29.11 \\
Grade attainment \\
$\quad$ Non-adjusted *** \\
$\quad$ Adjusted by enrolled age & 51.17 & 25.51 \\
$\begin{array}{l}\text { Note: }{ }^{\#} \text { This does not include those never enrol, *** Chi }{ }^{2} \text { test for the difference of schooling measures by nutrition } \\
\text { status shows a significant level of one per cent. }\end{array}$ & &
\end{tabular}

Table 3: The effects of childhood malnutrition on school attendance

\begin{tabular}{lrrrrr}
\hline Variables & \multicolumn{2}{c}{ School Attendance (Eq1) } & Marginal & \multicolumn{2}{c}{ Stunting (Eq2) } \\
\cline { 2 - 3 } & Coef. & Std. Err. & Effect & Coef. & Std. Err. \\
\hline Stunting & 0.108 & 0.806 & 0.014 & & \\
Child's age & -0.03 & 0.019 & 0.012 & $* * * 0.048$ & 0.011 \\
Gender of the child & 0.157 & 0.100 & 0.054 & 0.101 & 0.079 \\
Total household member & 0.005 & 0.018 & 0.006 & 0.017 & 0.014 \\
Log of household expenditure & 0.167 & 0.208 & -0.161 & $* * *-0.545$ & 0.120 \\
Father can read and write & $* * * 0.344$ & 0.103 & 0.026 & -0.05 & 0.087 \\
Mother can read and write & $* * 0.325$ & 0.140 & 0.015 & -0.065 & 0.105 \\
Clean housing condition & $* * 0.278$ & 0.110 & -0.032 & $* * *-0.212$ & 0.081 \\
Sanitary latrine & 0.155 & 0.118 & 0.059 & 0.116 & 0.090 \\
Wash hand & 0.011 & 0.115 & 0.074 & $* * * 0.217$ & 0.080 \\
Primary school & 0.241 & 0.274 & 0.154 & $* 0.378$ & 0.211 \\
Secondary girls' school & $* 0.988$ & 0.514 & -0.034 & -0.29 & 0.266 \\
Secondary mixed school & $* 0.478$ & 0.264 & -0.106 & $* * *-0.445$ & 0.157 \\
Distance to MBBS doctor & 0.00004 & 0.001 & 0.0002 & 0.001 & 0.001 \\
Availability of electricity & 0.082 & 0.203 & -0.026 & -0.109 & 0.158 \\
Constant & -0.165 & 0.827 & & $* * 0.921$ & 0.423 \\
$\rho$ & -0.068 & 0.493 & & & \\
\hline
\end{tabular}

Notes: ***, **, \&*indicates $1 \%, 5 \%$ and $10 \%$ level of significance respectively; $N=1222 ;$ marginal effects are only reported for the probability of due enrolment (Eq1); community dummies are dropped for brevity. 
Table 4: The effects of childhood malnnutrition on due enrolment

\begin{tabular}{lrrrrr}
\hline Variables & \multicolumn{2}{c}{ Due enrolment (Eq1) } & Marginal & \multicolumn{2}{c}{ Stunting (Eq2) } \\
\cline { 2 - 3 } & Coef. & Std. Err. & Effect & Coef. & Std. Err. \\
\hline Stunting & $* *-1.416$ & 0.577 & -0.267 & & \\
Child's age & $* * *-0.143$ & 0.041 & -0.020 & $* * * 0.06$ & 0.014 \\
Gender of the child & 0.071 & 0.094 & 0.024 & 0.057 & 0.088 \\
Total household member & $* 0.032$ & 0.017 & 0.010 & 0.018 & 0.016 \\
Log of household expenditure & 0.389 & 0.245 & -0.015 & $* * *-0.589$ & 0.136 \\
Father can read and write & 0.128 & 0.110 & 0.016 & -0.064 & 0.096 \\
Mother can read and write & $* * * 0.507$ & 0.150 & 0.084 & -0.073 & 0.113 \\
Clean housing condition & 0.095 & 0.134 & -0.020 & $* * *-0.26$ & 0.093 \\
Sanitary latrine & 0.155 & 0.106 & 0.050 & 0.11 & 0.100 \\
Wash hand & $* *-0.263$ & 0.132 & -0.023 & $* 0.175$ & 0.093 \\
Primary school & -0.02 & 0.281 & 0.066 & $* 0.418$ & 0.242 \\
Secondary girls' school & $* * * 1.09$ & 0.388 & 0.105 & -0.192 & 0.281 \\
Secondary mixed school & $* * 0.631$ & 0.283 & 0.013 & $* *-0.412$ & 0.164 \\
Distance to MBBS doctor & $* 0.0023$ & 0.001 & 0.0007 & 0.001 & 0.001 \\
Availability of electricity & 0.078 & 0.197 & -0.014 & -0.173 & 0.170 \\
Constant & 0.226 & 0.781 & & $* * 1.022$ & 0.481 \\
$\rho$ & 0.533 & 0.406 & & & \\
\hline
\end{tabular}

Notes: ***,**, \& * indicates $1 \%, 5 \%$ and $10 \%$ level of significance respectively; $N=985 ;$ marginal effects are only reported for the probability of due enrolment (Eq1); community dummies are dropped for brevity. 
Table 5: The effects of childhood malnnutrition on grade attainment

\begin{tabular}{|c|c|c|c|c|c|c|}
\hline \multirow[b]{2}{*}{ Variables } & \multicolumn{3}{|c|}{ Non-adjusted $S A G E$} & \multicolumn{3}{|c|}{ Adjusted SAGE } \\
\hline & Coef. & Std. Err. & $\begin{array}{r}\text { Marginal } \\
\text { effect }\end{array}$ & Coef. & Std. Err. & $\begin{array}{r}\text { Marginal } \\
\text { effect }\end{array}$ \\
\hline Stunting & $* * *-1.612$ & 0.283 & -0.319 & -0.843 & 0.695 & -0.074 \\
\hline Child's age & $* * *-0.113$ & 0.025 & -0.020 & $* * * 0.088$ & 0.017 & 0.028 \\
\hline Gender of the child & 0.065 & 0.082 & 0.028 & 0.1 & 0.099 & 0.027 \\
\hline Total household member & 0.022 & 0.015 & 0.008 & 0.013 & 0.018 & 0.008 \\
\hline Log of hh expenditure & 0.239 & 0.165 & -0.019 & -0.228 & 0.190 & -0.210 \\
\hline Father can read and write & $* * 0.225$ & 0.097 & 0.045 & $* * * 0.335$ & 0.130 & 0.007 \\
\hline Mother can read and write & $* * * 0.417$ & 0.123 & 0.079 & $* *-0.286$ & 0.129 & -0.051 \\
\hline Clean housing condition & $* * 0.205$ & 0.105 & 0.023 & -0.092 & 0.123 & -0.093 \\
\hline Sanitary latrine & 0.113 & 0.094 & 0.043 & 0.181 & 0.115 & 0.047 \\
\hline Hand wash & -0.162 & 0.102 & -0.006 & -0.008 & 0.117 & 0.054 \\
\hline Primary school & $* 0.378$ & 0.223 & 0.128 & 0.3 & 0.276 & 0.154 \\
\hline Secondary girls' school & $* * 0.691$ & 0.311 & 0.050 & -0.154 & 0.307 & -0.078 \\
\hline Secondary mixed school & $* * 0.45$ & 0.211 & -0.004 & 0.214 & 0.251 & -0.128 \\
\hline Distance to MBBS doctor & 0.001 & 0.001 & 0.000 & 0 & 0.001 & 0.000 \\
\hline Availability of electricity & 0.061 & 0.171 & -0.001 & 0.015 & 0.188 & -0.059 \\
\hline Constant & -0.195 & 0.580 & & 0.336 & 0.808 & \\
\hline$\rho$ & $* * * 0.69$ & 0.213 & & 0.445 & 0.434 & \\
\hline
\end{tabular}

Notes: $* * * * *$ and $*$ indicates $1 \%, 5 \%$ and $10 \%$ level of significance respectively; $N=985$; results of Eq2(Stunting) and community dummies are dropped for brevity. 


\section{References}

Alderman, H., Behrman, J. R., Lavy, V., and Menon, R. (2001). Child health and school enrolment: A longitudinal analysis. The Journal of Human Resources, 36:185-205.

Behrman, J. R. (1996). The impact of health and nutrition on education. The World Bank Research Observer, 11:23-37.

Behrman, J. R. and Lavy, V. (1998). Child health and schooling achievement: Association, causality and household allocations. Technical Report 97-023, Penn Institute for Economic Research.

Black, S. E., Devereux, P. J., and Salvanes, K. G. (2007). From the cradle to the labor market? the effect of birth weight on adult outcomes. Quarterly Journal of Economics, 122(1):409 - 439.

Becker, G., Lewis, G., 1973. On the interaction between the quantity and quality of children. The Journal of Political Economy, 81, S279-S288.

Becker, G.S., 1965. A theory of the allocation of time. Economic Journal, 75, 493-517.

Case, A., Fertig, A., and Paxson, C. (2005). The lasting impact of childhood health and circumstance. Journal of Health Economics, 24(2):365-389.

Chutikul, S. (1986). Malnourished children: an economic approach to the causes and consequences in rural Thailand. Technical Report 102, East-West Center.

Currie, J. and Moretti, E. (2007). Biology as destiny? short- and long-run determinants of intergenerational transmission of birth weight. Journal of Labor Economics, 25(2):231 $-263$. 
Edwards, L. N. and Grossman, M. (1980). The relationship between children's health and intellectual development. Technical Report 0213, National Bureau of Economic Research (NBER).

ESCAP (2005). Bangladesh demographic health survey (BDHS). Technical report, United Nations Economic and Social Commission for Asia and the Pacific.

Glewwe, P. and Jacoby, H. G. (1995). An economic analysis of delayed primary school enrollment in a low income country: The role of early childhood nutrition. The Review of Economics and Statistics, 77(1):156-169.

Glewwe, P., Jacoby, H. G., and King, E. M. (2001). Early childhood nutrition and academic achievement: a longitudinal analysis. Journal of Public Economics, 81(3):345-368.

Gomes-Neto, J. B., Hanushek, E. A., Leite, R. H., and Frota-Bezzera, R. C. (1997). Health and schooling: Evidence and policy implications for developing countries. Economics of Education Review, 16(3):271-282.

Grira, H. (2004). The determinants of grade attainment in low-income countries: Evidence from rural Bangladesh. The Developing Economies, 42(4):494-509.

Handa, S. and Peterman, A. (2007). Child health and school enrollment. Journal of Human Resources, 42(4):863 - 880.

Harbison, R. and Hanushek, E. (1992). Educational Performance of the Poor: Lessons from Rural North-east Brazil. Oxford University Press.

International Food Policy Research Institute (2001). Bangladesh: Commercial Vegetable and Polyculture Fish Production-Their Impacts on Income, Household Resource $\begin{array}{lll}\text { Allocation, } \quad \text { and } \quad \text { Nutrition, } & \text { 1996-1997 }\end{array}$ (datasets), http://www.ifpri.org/dataset/bangladesh-1. 
Jamison, D. T. (1986). Child malnutrition and school performance in China. Journal of Development Economics, 20(2):299-309.

Johnson, R. and Schoeni, R. (2007). The influence of early-life events on human capital, health status, and labor market outcomes over the life course. Research Report 07-616, Institute for Research on Labor and Employment, Population Studies Center Research Report 07-616.

Khanam, R., H. S. Nghiem, and L. B. Connelly (2009): Child Health and the Income Gradient: Evidence from Australia, Journal of Health Economics, 28, 805-817.

Khanam, R. and Ross, R. (2008). Child work and other determinants of school attendance and school attainment in Bangladesh. The 37th Australian Conference of Economists, 30 September-4 October 2008, Gold Coast, Australia.

Lawlor, D., Clark, H., Smith, G. D., and Leon, D. (2006). Intrauterine growth and intelligence within sibling pairs: Findings from the Aberdeen children of the 1950s cohort. Paediatrics, 117:894-902.

Murasko, J. E. (2008): An evaluation of the age-profile in the relationship between household income and the health of children in the United States, Journal of Health Economics, 27(6), 1407-1652.

Moock, P. R. and Leslie, J. (1986). Childhood malnutrition and schooling in the Terai region of Nepal. Journal of Development Economics, 20(1):33-52.

Oreopoulos, P., Stabile, M., Walld, R., and Roos, L. L. (2008). Short-, medium-, and longterm consequences of poor infant health. Journal of Human Resources, 43(1):88 - 138.

Pollitt, E. (1990). Malnutrition and Infection in the Classroom. UNESCO. 
Pollitt, E., Gorman, K. S., Engle, P. L., Martorell, R., Rivera, J., Wachs, T. D., and Scrimshaw, N. S. (1993). Early supplementary feeding and cognition: Effects over two decades. Monographs of the Society for Research in Child Development, 58(7):1-118.

Psacharopoulos, G. and Patrinos, H. A. (1997). Family size, schooling and child labor in Peruan empirical analysis. Journal of Population Economics, 10:387-405.

Ray, R. and Lancaster, G. (2005). The impact of children's work on school: Multi-country evidence. International Labour Review, 14:189-210.

Roodman, D. (2007). Cmp: Stata module to implement conditional (recursive) mixed process estimator. Technical report, Statistical Software Components S456882, Boston College Department of Economics.

Schultz, T. P. (1999). Health and schooling investments in Africa. Journal of Economic Perspectives, 13:67-88.

Singh, I., L. Squire and J. Strauss (1986). "A Survey of Agricultural Household Models: Recent Findings and Policy Implications". World Bank Economic Review, 1(1): 14979.

Smith, J. P. (2007). The impact of social economic status on health over the life course. Journal of Human Resources, 42:739-764.

Taylor, J. E. and I. Adelman (2003). “Agricultural Household Models: Genesis, Evolution, and Extensions". Review of Economics of the Household, 1: 33-58

United Nations Development Program (2008). Human development report 2007/2008. Technical report, United Nations Development Programs.

Waterlow, J. (1972). Classification and definition of protein-calorie malnutrition. British Medical Journal, 3:566-569. 